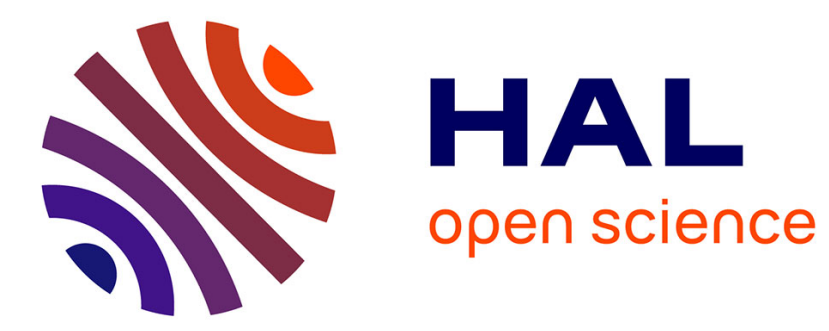

\title{
Structural Change, Specialisation and Regional Labour Market Performance: Evidence for the UK
}

Martin Robson

\section{To cite this version:}

Martin Robson. Structural Change, Specialisation and Regional Labour Market Performance: Evidence for the UK. Applied Economics, 2009, 41 (03), pp.275-293. 10.1080/00036840601007278 . hal-00582062

\section{HAL Id: hal-00582062 \\ https://hal.science/hal-00582062}

Submitted on 1 Apr 2011

HAL is a multi-disciplinary open access archive for the deposit and dissemination of scientific research documents, whether they are published or not. The documents may come from teaching and research institutions in France or abroad, or from public or private research centers.
L'archive ouverte pluridisciplinaire HAL, est destinée au dépôt et à la diffusion de documents scientifiques de niveau recherche, publiés ou non, émanant des établissements d'enseignement et de recherche français ou étrangers, des laboratoires publics ou privés. 


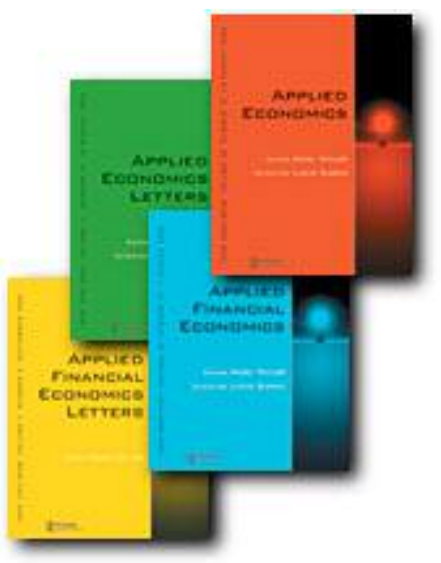

\section{Structural Change, Specialisation and Regional Labour Market} Performance: Evidence for the UK

\begin{tabular}{|r|l|}
\hline Journal: & Applied Economics \\
\hline Manuscript ID: & APE-06-0055.R1 \\
\hline Journal Selection: & Applied Economics \\
\hline JEL Code: & $\begin{array}{l}\text { J64 - Unemployment: Models, Duration, Incidence, and Job Search } \\
<\text { J6 - Mobility, Unemployment, and Vacancies < J - Labor and } \\
\text { Demographic Economics, R12 - Size and Spatial Distributions of } \\
\text { Regional Economic Activity < R1 - General Regional Economics < R } \\
\text { - Urban, Rural, and Regional Economics }\end{array}$ \\
\hline Keywords: & \begin{tabular}{l} 
Structural Change, Specialisation, Regional Labour Markets \\
\hline
\end{tabular} \\
\hline
\end{tabular}

powered by ScholarOne
Manuscript Central 


\title{
Structural Change, Specialisation and Regional Labour Market Performance: Evidence for the UK
}

\author{
Martin Robson \\ Department of Economics and Finance \\ University of Durham \\ 23-26, Old Elvet \\ Durham \\ DH1 3HY \\ Email: m.t.robson@durham.ac.uk
}

July 2006

\begin{abstract}
While structural change and regional differences in the pattern of employment specialisation are widely perceived to be significant factors in accounting for disparities in the labour market performance of regions in the United Kingdom, there have been relatively few recent attempts to gather detailed evidence on this issue. The current study aims to fill this gap by examining the effects of structural change and associated changes in the pattern of employment specialisation on three key indicators of regional labour market performance: the rate of employment growth, the unemployment rate and the rate of nonemployment. The findings indicate that while industry structure has statistically significant effects on regional labour market performance, the quantitative significance of these effects is relatively small.
\end{abstract}

Keywords: Structural change Specialisation Regional labour markets

JEL codes: J64; R12 


\section{Introduction}

The past thirty-five years have seen significant changes in the structure of the United Kingdom economy, in particular the decline of many traditional manufacturing and primary sector industries and the emergence of a number of new flourishing fields of activity, mainly in the service sector. The causes of these structural shifts have been widely debated. Explanations that have been put forward include the effects of changes in the composition of demand due to rising consumer incomes, competition from low-wage developing economies, and the crowding out of private sector activities as a result of the growth in the size of the non-market public sector (Bacon and Eltis, 1976). ${ }^{1}$ The process of structural change has generated significant upheaval in the labour market as jobs have been reallocated from declining to growing sectors, and led to significant changes in the pattern of industrial specialisation at both the national and regional level (Wren and Taylor, 1999; Robson, 2006).

Inherited differences in industry structure mean that the impact and effects of structural change have been different for different regions. In the United Kingdom, regions such as Wales and the North East of England are often perceived to have suffered because of their traditional concentration of employment in industries such as coal mining and iron and steel production, in which the UK has experienced a long-term decline in its share of world markets. ${ }^{2}$ In contrast, London and the South East of England are perceived to have benefited as a result of their specialisation in thriving service sector activities, such as financial and business services.

\footnotetext{
${ }^{1}$ For a useful textbook summary of competing explanations see chapter 1 of Griffiths and Wall (2004).

${ }^{2}$ See, for example, Erdem and Glyn (2001) and O'Leary et al, (2005).
} 
Evidence produced by Wren and Taylor (1999), and supported in the main by findings reported in Robson (2006), suggests that as a result of structural change, regions in the United Kingdom have become increasingly similar in terms of the extent to which employment is specialised in particular industries. In particular, employment in all regions is becoming increasingly concentrated in the service sector. Furthermore, within the service sector itself, an increasing share of the total number of jobs is located within a relatively small number of industries.

While structural change and regional differences in the pattern of employment specialisation are widely perceived to be significant factors in accounting for disparities in the labour market performance of UK regions, there have been relatively few recent attempts to gather detailed evidence on this issue. $^{3}$ The current study aims to fill this gap in the literature by carrying out a detailed investigation of the effects of structural change and associated changes in the pattern of employment specialisation on three key indicators of regional labour market performance: the rate of employment growth, the unemployment rate and the rate of non-employment.

There are a number of ways in which the labour market performance of a region could, in principle, be influenced by its prevailing industry structure. Firstly, in the short-run, the industry composition of employment within a region may have a significant effect on the region's vulnerability to the effects of aggregate shocks. Other things equal, regions in which there is a relative

\footnotetext{
${ }^{3}$ Taylor and Bradley (1994) find that, other things equal, the impact of the 1990-2 recession in the UK economy was weaker in areas with a relatively high proportion of employment in the primary sector. Other studies that have investigated the role of industry mix in contributing to an explanation for UK regional unemployment disparities include Cheshire (1973), Dixon and Thirlwall (1975), and Taylor and Bradley (1983).
} 
concentration of employment in 'cyclically sensitive' industries will tend to experience wider cyclical variations in employment and unemployment than regions that are specialised in more cyclically stable industries. Secondly, structural changes resulting from longer-term shifts in the pattern of labour demand across industries may generate 'reallocation shocks' that lead to increases in regional unemployment as labour that is displaced from declining industries takes time to be absorbed into the new growing sectors of the economy (Lilien, 1982). Finally, evidence from a number of studies suggests that a region's labour market performance may be influenced by the degree of specialisation or diversity in the region's industry mix (e.g. Diamond and Simon, 1990; Neumann and Topel, 1991). For example, a region that is characterised by a diverse industry employment mix may be less vulnerable to the effects of adverse shocks to aggregate demand than one in which employment is concentrated within a relatively small number of related industries.

To examine the effect of industry structure on regional labour market performance this study makes use of annual data on employment in 30 industries for each of the 12 Government Office Regions for the period $1975-2001 .^{4}$ For each region, we construct measures of the effects of aggregate industry employment shocks, the effects of reallocation shocks, and the degree of diversity or specialisation in regional employment. These measures are used as explanatory variables in panel data regressions for, in succession: the rate of growth of regional employment; the regional unemployment rate; and the rate of non-employment. The latter is important as changes in rates of labour force

\footnotetext{
${ }^{4}$ The Government Office Regions replaced the traditional Standard Statistical Regions as a basis for the compilation of official statistics in 1996. The employment data were kindly supplied by Katerina Homenidou of Cambridge Econometrics.
} 
participation in recent years, particularly amongst prime-age men, mean that a focus on regional unemployment rates alone may give a misleading impression of the extent of regional disparities in the number of individuals without work (Erdem and Glyn, 2001; Fothergill, 2001; O'Leary et al, 2005). The results of these panel data regressions may be used to gain insights into the contribution that changes in industry employment structures have made to the performance of individual regional labour markets.

The pattern of the remainder of the paper is as follows. In Section 2 we discuss the data on the industry composition of employment by region, highlighting the key structural shifts that have taken place over the past 30 years. In addition, this section presents data on the key indicators of regional labour market performance that are the focus of the paper's analysis, i.e. the rate of growth of employment, the rate of unemployment and the non-employment rate where the latter is defined as the proportion of the population of working age that is either economically inactive or unemployed. Section 3 provides details of the measures we use to examine the effects of industry structure on regional labour market performance and reports the results of the study's econometric analysis. The effects of structural change are then illustrated through an assessment of the contribution made by changes in the industry composition of regional employment to the pattern of regional unemployment disparities in the UK.

\section{Changes in the Industry Composition of Employment and Regional Labour Market Performance.}

Table 1 highlights the key changes that have taken place in the period since 1975 in the sectoral distribution of employment at the regional level. The Table shows the percentage of employment in each Government Office Region 
in each of six main industry groups for the years 1975 and 2001. As noted above, the main feature of this data is the remarkable decline in the share of employment in manufacturing experienced in each region and the rise in the importance of the service sector. Also notable, however, is the collapse in employment in the Mining and Quarrying sector, which has had a particular impact on employment in the North East, Wales, the East Midlands and Yorkshire and Humberside.

In absolute terms, the decline in the share of manufacturing employment has been greatest in the regions in which the initial share of manufacturing was highest - the West and East Midlands, the North West, Yorkshire and Humberside, and the North East. However, in proportionate terms the experience of manufacturing decline has been similar across all regions: in general, by 2001, the share of employment in manufacturing was about a half of its level in $1975^{5}$ In contrast to the experience in manufacturing, the growth of the share of employment in the service sector has been greatest in both absolute and proportionate terms in the regions that initially had the lowest service sector employment shares. The implication is that over the period since 1975 there has been a degree of convergence in the sectoral distribution of employment across regions, driven by the growth in service sector employment.

More detailed evidence on the extent of convergence in regional employment structures is presented in Table 2 and Figure 1, which show the patterns and trends in the Coefficient of Regional Specialisation (CRS) for the 12 Government Office Regions using data on employment in 30 industries. ${ }^{6} \mathrm{CRS}$ is calculated as one-half of the sum of absolute deviations of the share of total

\footnotetext{
${ }^{5}$ Notable exceptions to this trend are the cases of Wales and London. In the former, the share of manufacturing employment in 2001 was approximately $65 \%$ of its level in 1975; while in London the share of employment in manufacturing had declined to almost one-third of its 1975 level.

${ }^{6}$ The industries are defined in Appendix Table A.
} 
regional employment in industry $i$ from the industry's share of total national employment; i.e. as:

$$
C R S=(1 / 2) \sum_{i=1}^{n}\left|\left(x_{i r} / x_{r}\right)-\left(x_{i} / x_{N}\right)\right|
$$

where $x$ denotes employment and the $i, r$ and $N$ subscripts denote the industry, region and national economy, respectively. A value of CRS equal to zero implies that the structure of employment in a region is identical to that of the national economy. Higher values of the index imply an increasingly divergent regional employment structure.

The data in Table 2 and Figure 1 indicate that over the period 1975-2001, with the exception of the London region and to a lesser extent Scotland, there has been a tendency for regional employment structures to become increasingly similar to that of the UK economy as a whole. From the mid-1990s onwards, however, the tendency towards convergence appears to have flattened out and in some cases to have been at least partially reversed. In absolute terms, the greatest decline in the level of employment specialisation has occurred in Northern Ireland, which traditionally has been the region that has deviated furthest from the national employment pattern but which recently has yielded this distinction to London.

\section{Regional Labour Market Performance}

The pattern of regional labour market performance in the United Kingdom is often characterised in terms of a 'north-south divide', with regions in the south of the country tending to perform relatively well while those in the north - broadly defined to include both Wales and Northern Ireland - tend to 
exhibit a weaker performance (see e.g. Blackaby and Murphy, 1995; Rowthorn, 2000). Evidence in support of this general characterisation is apparent in Figures 2 and 3, which show, respectively, data on levels of employment and the claimant count rate of unemployment for the 12 Government Office Regions. ${ }^{7}$

For the most part, the data are supportive of the view that there is a northsouth divide in regional labour market performance. In particular, in the period under consideration, levels of employment growth were strongest in the South East, South West and East of England, while these regions experienced unemployment rates that were persistently below the average for the UK as a whole. ${ }^{8}$ In contrast, the North East and North West have experienced declining levels of employment (relative to the start of the period) and relatively high rates of unemployment. Exceptions to the general view are apparent, however. Most notably, employment growth in London has been relatively stagnant throughout most of the period under consideration - except until the mid 1990s - while Northern Ireland, despite its high rates of unemployment, has experienced significant growth in employment.

Trends in rates of economic inactivity, in particular amongst prime-age males, have led to an increasing recognition that a focus on rates of unemployment alone may give a misleading impression of the extent of regional disparities in the extent of joblessness in the UK economy. In general, economic activity rates amongst prime-age males have been declining since the 1970s and since the mid-1980s this decline has been particularly pronounced in the regions characterised by relatively high average rates of unemployment (Erdem and

\footnotetext{
${ }^{7}$ The employment data are from Cambridge Econometrics, while the source for the claimant count data is the website of the Office for National Statistics (ONS), www.statistics.gov.uk . ${ }^{8}$ An exception occurred in the recession of the early 1990 s, when the unemployment rate in the South East rose to a level equal the UK average. However, this period proved to be short lived.
} 
Glyn, 2001; Fothergill, 2001; Faggio and Nickell, 2005). Any assessment of regional labour market performance needs therefore to consider developments in the rate of non-employment rather than focussing simply on the rate of unemployment.

Figure 4 shows data on rates of non-employment amongst members of the working age population (aged 15-64 for males, 15-59 for females) for the 11 Government Office Regions of Great Britain, for the years 1981-2001. ${ }^{9}$ It should be noted that the employment data used to calculate these figures are compiled from workplace data, while the population figures are based on place of residence. The high level of commuting inflows into London (mostly from the South East) means that the data give a misleading impression of the extent of non-employment amongst households in the London Government Office Region (GOR). Labour Force Survey data indicate that the rate of non-employment amongst households in London is on average roughly comparable to that of a typical 'northern' region. ${ }^{10}$ Despite this caveat, it is clear that the data on nonemployment rates reinforce the view that there are significant north-south disparities in regional labour market performance.

\section{The Effects of Industry Structure on Regional Labour Market Performance: Data and Econometric Analysis.}

To what extent are these regional disparities in labour market performance attributable to the structural differences between regions and the changes to the pattern of regional employment specialisation that have occurred

\footnotetext{
${ }^{9}$ Data for Northern Ireland is available only from 1992 and is therefore excluded from this analysis.
} 
as a result of structural change? That is the question that we attempt to answer in this section.

Structural differences between regions in the industry composition of employment are likely to have implications for the way in which labour market performance in different regions is influenced by the effects of aggregate shocks to the economy. It is well known, for example, that industries vary in their sensitivity to the effects of aggregate shocks, such as fluctuations in the level of aggregate demand. Regions in which there is a relatively high concentration of employment in such industries will therefore tend to exhibit greater vulnerability to the effects of aggregate shocks than other regions and this is likely to be reflected in their labour market performance. If regions have become increasingly similar in the extent of their exposure to 'high shock' industries then, for example, this would be expected to lead to a decline in the dispersion of regional rates of employment growth and unemployment.

Studies of the effect of industry structure on regional labour market performance have traditionally been based on the application of 'shift-share' analysis. However, it is recognised that this technique is subject to a number of weaknesses (see Fothergill and Gudgin, 1982). In this study we attempt to capture the effect of a region's industry structure on its vulnerability to the effects of aggregate shocks by following Neumann and Topel (1991) in defining a variable, Shock $k_{r t}$, which measures the predicted impact on region $r$ of disturbances to aggregate industry employment. The variable is constructed as:

\footnotetext{
${ }^{10}$ In the Labour Force Survey for the spring quarter of 2005, the non-employment rate for the London GOR (30.6\%) was the highest amongst the British regions. In the UK as a whole, only Northern Ireland had a higher non-employment rate.
} 
Shock $k_{r t}=\sum_{i=1}^{n} e_{i r t} \hat{v}_{i t}$

where $\mathrm{e}_{i r t}$ denotes the share of industry $i$ in employment in region $r$ at period $t$

and $\hat{v}_{i t}$ denotes a disturbance to the log of aggregate employment in industry $i$. The latter is obtained as the residuals from an autoregressive model of the form:

$\ln E(L)_{i t}=\alpha_{i}+v_{i t}$

where $E_{i t}$ denotes aggregate employment in industry $i(i=1, \ldots, \mathrm{n})$ and $L$ is the lag operator.

Table 3 shows values of Shock $k_{r t}$ for selected years during the time period covered by the data sample. Note that given the method used to construct the data the reported figures represent percentage deviations of regional employment. The data highlight the impact of the cyclical fluctuations experienced in the UK economy over the past thirty years. In particular, the large negative values recorded for 1981 and 1991 reflect the impact of the severe cyclical recessions which were experienced in the early 1980s and early 1990s as a result of rising interest and exchange rates and - in the case of the former - the sharp OPEC-induced increase in oil prices at the turn of the decade. The data show that relative to other regions the industry composition of employment in the West Midlands has tended to make it particularly sensitive to the effects of industry employment shocks, while for Northern Ireland the opposite is true. The figures provide an interesting insight into the way in which the industry composition of employment contributed to the regional impact of the recessions of the early 1980s and early 1990s. For example, the data suggest that in 1981 the size of the negative shock to employment in the West Midlands would have been reduced by 1.3 percentage points if it had possessed the same industry 
employment structure as Northern Ireland, while in 1991 the difference would have been 1.2 percentage points.

Changes in the value of Shock $k_{r t}$ may be expected to give rise to short-run deviations of regional unemployment rates from their long-run equilibrium values. The duration of these departures from equilibrium will depend upon the speed with which regional adjustment mechanisms - relative wages, interregional migration and labour force participation rates - act to restore the initial pattern of equilibrium unemployment differentials. Relative to the U.S., the speed of regional adjustment mechanisms in European labour markets has been found to be relatively slow (Decressin and Fatás, 1995). Temporary shocks to aggregate industry employment may therefore have quite long-lived effects on regional labour market performance.

The above point notwithstanding, disturbances generated by aggregate industry employment shocks are essentially a short-run cyclical phenomenon. More persistent effects on regional labour market performance may be expected to result from permanent shifts in the pattern of labour demand across industries that necessitate a reallocation of workers between sectors. In the absence of frictionless movements of workers between sectors, such reallocation shocks may lead to 'structural unemployment' within regions as displaced workers take time to adjust to the skills required in growing sectors. For older workers in particular, the costs of retraining may outweigh the benefits and therefore with little prospect of re-employment some workers may find it optimal to leave the labour force altogether. Developing this theme, Lilien (1982) devises an index to capture the effects of reallocation shocks, which is based on the standard deviation of relative employment growth across industries. Using this index, he 
presents evidence that appears to show that much of the time-series variation in the U.S. unemployment rate in the period since World War II can be explained by the effects of reallocation shocks. The findings obtained by Lilien have since been subject to criticism by a number of authors (e.g. Abraham and Katz, 1986) - mainly on the grounds that he ignored the potential correlation between his index of reallocation shocks and the effects of aggregate cyclical disturbances. Nevertheless, the index devised by Lilien remains a potentially useful indicator of the effects of reallocation shocks on the economy.

For each region, we calculate Lilien's index as:

$$
\text { Lilien }_{t}=\left[\sum_{i=1}^{n}\left(x_{i r t} / x_{r t}\right)\left(\Delta \log x_{i r t}-\Delta \log x_{r t}\right)^{2}\right]^{1 / 2}
$$

where $x_{i}$ is employment in industry $i(i=1,2, \ldots, \mathrm{n})$ and $x_{r}$ is total regional employment, with $\Delta$ denoting the first difference operator. The data, which are tabulated for selected dates in Table 4, show that over the period 1975-2001 the incidence of reallocation shocks tended to be highest in the North East region, with Wales, Scotland and the East Midlands a little way behind. In contrast, the incidence of reallocation shocks is found to be lowest in the South East.

A number of studies have suggested that the extent of specialisation or diversity in a region's industry mix may have a significant effect on its labour market performance. For example, a specialised industry mix may provide a favourable environment for regional employment growth by presenting opportunities for spillovers between firms of productivity enhancing innovations. ${ }^{11}$ In contrast, in regions with a diverse employment mix there may be greater scope for the effects of negative shocks to industry employment to be 
absorbed through inter-industry labour mobility, thus enabling the region to sustain a relatively low rate of unemployment (Simon, 1988). ${ }^{12}$

Building upon earlier search-theoretic models from the macroeconomic literature on unemployment (e.g. Lucas and Prescott, 1974), Neumann and Topel (1991) develop a model in which equilibrium regional unemployment disparities can be explained as a result of differences between regions in their degree of exposure to the risk of industry employment shocks. The essence of their model is that regions that are characterised by a relatively high covariance of labour demand shocks between industries, or in which there is a relatively high variance of within-industry shocks, will tend to exhibit relatively high equilibrium rates of unemployment/non-employment, other things equal. Conversely, in regions in which the covariance structure of labour demands is such that workers are able to counter the effects of local shocks through inter-sectoral mobility the equilibrium unemployment rate will tend to be relatively low. In this context, 'diversity' is measured - in inverse form - by the extent of a region's exposure to the risk of industry-wide labour demand shocks.

The measure that Neumann and Topel use to quantify the extent of a region's exposure to the risk of labour demand shocks is calculated as:

$$
\operatorname{Risk}_{r t}=e_{r t}^{\prime} \hat{\Omega}_{r} e_{r t}
$$

where $e_{r t}$ is the (n $\mathrm{x} 1$ ) vector of industry employment shares in region $\mathrm{r}$ at time $\mathrm{t}$ and

$\hat{\Omega}_{r t}=T^{-1} \sum_{t} \hat{V}_{r t} \hat{V}_{r t}^{\prime}$

\footnotetext{
${ }^{11}$ This is an example of an agglomeration economy, as described for example by Rosenthal and Strange (2004).

12 The basic idea here can be traced at least as far as Marshall (1920).
} 
is the estimated variance-covariance matrix of demand disturbances in region $r$. The vector

$\hat{V}_{r t}=\left(\hat{\mathrm{V}}_{1 r t}, \hat{\mathrm{v}}_{2 r t}, \ldots, \hat{\mathrm{V}}_{n r t}\right)^{\prime}$

is the vector of estimated industry employment shocks in year t, the elements of which are derived from a regression equation of the form of equation (2) but estimated specifically for each region. The variable Risk $_{r t}$ therefore allows for the effect of both aggregate and region-specific employment disturbances. ${ }^{13}$

Data on the value of Risk are plotted in Figure 5 and tabulated for selected intervals in Table 5. For most regions, changes in the industry composition of employment since 1975 appear to have led to a small trend decline in the extent of exposure to regional employment shocks. The notable exception is the case of the North East, where structural changes have led to a much more marked decline in the risk of labour demand shocks.

A number of measures of regional economic specialisation or diversity exist in the literature. ${ }^{14}$ As an alternative to the Neumann and Topel (1991) measure, we experiment with the inclusion of a second, albeit less sophisticated, measure of specialisation or diversity in a region's industry employment mix, namely the Coefficient of Absolute Regional Specialisation (CARS) In contrast to the Coefficient of Regional Specialisation $(C R S)$ tabulated earlier, in which the industry structure of employment within a region is compared with that in the economy as a whole, CARS is an index of absolute specialisation in regional

\footnotetext{
${ }^{13}$ Note that the specification of equation (6) assumes that the variance-covariance structure of labour demand disturbances within regions is constant over time. Therefore any changes in the value of Risk within a region are due to changes in the industry composition of employment within the region. An alternative, more complex, procedure would be to allow the structure of covariances to change over time but this would require a specification of how $\Omega$ evolves, which would be difficult to implement empirically.
} 
employment. It is calculated as the coefficient of variation of employment in each industry, i.e. as:

$C A R S=\left[\sum_{i=1}^{n}\left(x_{i}-\bar{x}_{i}\right)^{2} /(n-1)\right]^{1 / 2} / \overline{x_{i}}$

where $\bar{x}_{i}=\sum_{i=1}^{n} x_{i} / n$

Higher values of CARS indicate an increasing dispersion of employment across industries and hence an increasing degree of specialisation. Values for this index, which are tabulated in Table 6, indicate that over the period under consideration, employment in all regions has become increasingly specialised in a relatively small number of industries, a phenomenon chiefly associated with the increasing importance of service sector employment.

\section{Econometric Analysis}

To analyse the effects of changes in the industry composition of employment on regional labour market performance, using our various measures of the potential impact of industry composition effects, we estimate panel data regressions of the basic form:

$y_{r t}=\alpha+\beta_{1}$ Shock $_{r t}+\beta_{2}$ Lilien $_{r t}+\beta_{3}$ Specialisation $_{r t}+\varphi Z_{r t}+\gamma_{t}+\varepsilon_{r t}$

where $y_{r t}$ is our chosen measure of labour market performance, which is either the rate of employment growth, $\Delta \ln e$, the $\log$ of the unemployment rate, $u$ (based on the claimant count measure of unemployment), or the log of the rate of non-employment, ner. On the right hand side of equation (9), Specialisation is measured either by the Neumann and Topel (1991) measure of regional

\footnotetext{
${ }^{14}$ For a recent review, see Chandra (2005), who develops a new measure similar in spirit to the measure of Risk devised by Neumann and Topel (1991).
} 
employment risks, Risk, or the CARS index of regional employment specialisation. The vector $\boldsymbol{Z}$ represents a vector of control variables, the components of which differ according to the specification of the dependent variable but which always includes a set of regional fixed effects. The latter are included to capture the effect of unobserved factors that lead to persistent differences in regional labour market performance that are not picked up by the other terms in the equation. The term $\gamma_{t}$ denotes a period effect common to all regions. This captures the influence of common aggregate factors that might be expected to influence regional labour market performance, including aggregate demand and supply shocks (interest rate changes, oil price shocks etc.) and changes in labour market institutional variables such as reforms to the unemployment benefit system (e.g. the replacement of unemployment benefit with Job-seekers' Allowance) and the introduction of the National Minimum Wage. ${ }^{15}$ The inclusion of these period effects means that the parameter on the Shock variable, $\beta_{1}$, captures the effect of inter-regional variations in $S h o c k_{r t}$, that are caused exclusively by differences between regions in the industry composition of employment. ${ }^{16}$

In the estimation, we allow for lags in the effect of changes in the explanatory variables by including up to two lags of each variable in the initial estimated equation. In addition, in some specifications of the equation a lagged dependent variable is included. This necessitates the use of a GMM estimator in

\footnotetext{
${ }^{15}$ In addition, the effects of changes to the method of calculating the claimant count - of which there were several during the period under study - should, for the most part, be absorbed by the period effects.

${ }^{16}$ We experimented with a specification in which allowance was made for the effects of spillovers from industry employment shocks in contiguous regions but in none of the estimated equations did these effects turn out to be statistically significant. Hence, no further reference to this issue is included in the discussion of the results reported below.
} 
order to overcome the biases that would otherwise result from the estimation of a dynamic panel data model with fixed effects. ${ }^{17}$

Prior to the estimation of our panel data regressions, we carry out an exploratory exercise to test for the presence of unit roots in the main variables of interest. For this purpose, we use the CIPS test developed recently by Pesaran (2005). This test, which provides a test of the null hypothesis of a unit root against the alternative of stationarity, is an extension to the panel unit root test devised by Im, Pesaran and Shin (2003) that allows for the presence of non-zero correlations between the time-series of the individual cross-section units. The results of this exercise are reported in Table 7.

The test statistics indicate that the rate of employment growth, our measure of industry employment shocks, Shock, and the Lilien index are stationary variables, while regional unemployment rates, the rate of nonemployment, Risk and CARS are characterised by the presence of unit roots. The result for the variable Shock is as would be expected given the manner in which this variable is constructed, while the finding for Risk is consistent with the visual evidence from the plot of this variable in Figure 5. In principle, the log of the rate of unemployment and the log of the non-employment rate should be classed as stationary variables, as they are derived from variables that are bounded to lie between zero and one. The test results for these series are probably best interpreted as indicating that over the period under consideration the variables exhibit a high degree of persistence such that they behave as if they possess a unit root. In turn, the results for the exercise as a whole may be interpreted as providing a preliminary indication of the likelihood that we may

${ }^{17}$ In practice, we use the difference GMM estimator of Arellano and Bond (1991). 
expect to find a long-run or simply a short-run relationship between a particular measure of industry structure effects and our chosen indicators of regional labour market performance. ${ }^{18}$

For the main econometric investigation, a general-to-specific modelling approach is adopted in which we start with an initial unrestricted dynamic specification (including, as noted above, up to two lags of the explanatory variables) and test down to give a final reported equation following the deletion of a number of insignificant terms. The dynamics of the relationship between the explanatory variables and the relevant measure of regional labour market performance are modelled flexibly, allowing these to be determined by the data.

We begin by reporting results from an analysis of the determinants of the rate of regional employment growth, which are presented in Table 8. Regional population density is included as an additional explanatory variable in the initial specification for regional employment growth, following evidence from a number of studies of an 'urban-rural shift' in the spatial distribution of employment in the United Kingdom, most notably in manufacturing industry but also in services (see, for example, Fothergill and Gudgin, 1982; Rowthorn, 2000). In addition - though with contrasting implications for the sign of the estimated relationship - rising population density may be associated with higher levels of consumer demand, providing further justification for the inclusion of terms in this variable. ${ }^{19}$

\footnotetext{
${ }^{18}$ It is also worth bearing in mind that the power of panel unit root tests depends on the presence of a reasonably long time-series dimension to the data - a minimum of 20 observations as a rough rule of thumb. While for most of our variables the number of observations in the data series is a little above this threshold, in the case of the log of the rate of non-employment it is marginally below.

${ }^{19}$ Population density is defined as number of persons per square kilometre. The regional population figures are taken from NOMIS, www.nomisweb.ac.uk, while the data on land area are from Regional Trends.
} 
Data for regional population density is available only from 1981, hence the equations for regional employment growth (which include up to two lags of the explanatory variables) are estimated using data for 1983-2001, the latter being the latest date for which data is available. Column (1) of Table 8 shows the results obtained from an equation in which the Neumann-Topel measure, Risk, is included to capture the effects of specialisation or diversity in a region's industry mix. The results indicate that, as might be expected, positive shocks to industry employment have a positive effect on the overall rate of regional employment growth, though the effect is partially reversed in the longer term. Moreover, the effects of changes in the value of Shock appear to be quite persistent, showing up as significant with a lag of up to two years. The coefficients on the terms in Risk indicate that a higher degree of specialisation in employment - and hence a relatively high exposure to the risk of industry employment shocks - has a positive effect on the rate of regional employment growth both in the short-run and in the long-run. While the validity of this finding may be called into question by the evidence from the panel unit root tests, which suggested that while employment growth may be a stationary variable Risk may be I(1), the effect seems to be statistically well-determined. The finding that specialisation is associated with a higher rate of employment growth is in contrast to the evidence from other studies, most notably that of Glaeser et al (1992), who find that for cities in the USA, greater diversity rather than specialisation provides a stimulus to employment growth. ${ }^{20}$ The most likely explanation for the result obtained

\footnotetext{
${ }^{20}$ Similarly, for Canada, Shearmur and Polèse (2005) report that in general greater initial diversity in local employment structures tends to be associated with greater subsequent employment growth. In contrast, however, for urban areas they find evidence that in the late 1990s increasing specialisation was associated with more rapid employment growth, suggesting that the relationship between diversity and employment growth may be both area and periodspecific.
} 
here is that within the UK regions a high degree of employment specialisation provides opportunities for the transmission of spillover effects between firms of employment creating innovations.

Further down the column, there is evidence - albeit below conventional levels of statistical significance - that changes in the Lilien index of sectoral shifts are associated with relatively low rates of employment growth, suggesting that structural change may act to impede the performance of regional labour markets. In contrast, lagged growth in regional population density has a strong positive effect on regional employment growth, suggesting that rising population density may be associated with growth in local levels of labour demand.

In column (2), we investigate the potential effects of industry specialisation a little further by breaking down the measure Risk into its two constituent components: the component that is due to the within-industry variance of shocks, RiskV, and a second component that is due to the covariance of shocks between industries, RiskC. The results indicate that the two components of Risk are broadly similar in their effects on regional employment growth, though the covariance component has a slightly stronger positive effect.

In column (3), the measure of Risk is replaced with the CARS index of employment specialisation. In this case, the coefficient for the first difference of CARS suggests that increasing specialisation has a weakly positive effect on regional employment growth, which is broadly supportive of the results from the previous two columns. The results in this column suggest, in addition, a slightly stronger negative effect on employment growth from changes in the Lilien index.

In Table 9, we shift attention to the unemployment rate as a measure of regional labour market performance and report estimates of equations with the 
natural logarithm of the regional unemployment rate as the dependent variable. Two lags of the dependent variable are included in the equations, in order to capture the dynamics in the relationship between the regional unemployment rate and its determinants. As a consequence of the inclusion of these terms, the Arellano-Bond GMM estimator is used to correct for the biases that would otherwise result from the correlation between the lagged dependent variable and the regional fixed effects. As is well known, the differencing procedure involved in the implementation of the Arellano-Bond estimator leads to first order serial correlation in the disturbance term of the estimated equation. The validity of the estimator hinges on the absence of second order serial correlation from the regression disturbances, a condition which the relevant test statistic indicates is satisfied in the case of the three equations reported in Table $9 .{ }^{21}$

As in the equations for regional employment growth, shocks to industry employment appear to be a significant determinant of regional unemployment rates, with effects that are quite strongly persistent. ${ }^{22}$ The coefficient for the second lag of the Lilien index is also statistically significant, indicating that sectoral shifts are a significant contributor to regional unemployment disparities. The evidence on the effects of employment specialisation/diversity indicates that in general, a high or rising degree of specialisation has a positive effect on the regional unemployment rate, a finding that appears to contradict the evidence from the equations for regional employment growth. However, the effects on the regional unemployment rate are only weakly determined. ${ }^{23}$ Perhaps the most

\footnotetext{
${ }^{21}$ The estimation period for these equations is 1978-2001.

${ }^{22}$ Note, however, that for each of the three specifications shown in the Table the coefficient for the one-year lag of Shock was statistically insignificant and this term was therefore deleted from the equation.

${ }^{23}$ In contrast, Neumann and Topel (1991) find that the level of Risk has a strong positive effect on the rate of unemployment in U.S. states.
} 
interesting finding in this context is the evidence from the estimates reported in column (2), which indicates that the within-industry variance of employment shocks and the covariance of shocks across industries appear, on balance, to have opposite effects on the regional unemployment rate. Again, however, while the coefficient for the contemporaneous value of the covariance of industry shocks has a statistically significant negative value, on the whole these results are not particularly well determined. $^{24}$

Finally, we turn to our third measure of regional labour market performance, the rate of non-employment. As noted in earlier sections, the numerator of the non-employment rate includes individuals who are registered as unemployed plus those outside the labour force, and thus this variable represents a more comprehensive measure of the extent of joblessness within a region than the rate of unemployment alone. In this analysis, we include as additional explanatory variables two demographic control variables: the percentage of the working age population in a region that is male (PMale) and the percentage of the working age population aged 25 or under (PYoung). ${ }^{25}$ The former is included in recognition of the fact that while differences in labour force participation rates between males and females in the United Kingdom have tended to narrow over the past twenty years, participation rates nevertheless tend to be higher amongst males than amongst females. The latter variable is included to control for variations in non-employment rates that may be expected to occur across different age groups within the working age population. ${ }^{26}$

\footnotetext{
${ }^{24}$ Experiments with different lag structures do not alter the overall finding of a relatively weak statistical relationship between Risk (or its components) and the rate of regional unemployment. Detailed results are available from the author, on request.

${ }^{25}$ The population data used to construct these variables are obtained from NOMIS.

${ }^{26}$ As an alternative means of capturing the effects of variations in the age composition of the working age population we experimented with the inclusion of terms in the proportion of workers
} 
The equations for regional rates of non-employment are estimated using data for 1983-2001, with the absence of data for Northern Ireland meaning that the sample size for these regressions is limited to 209 observations. The results reported in Table 10 indicate that as in the analysis of regional unemployment rates, there is strong evidence that differences in industry structure between regions lead to differences in the effects of industry-wide employment shocks on regional labour markets. ${ }^{27}$ Regions that, as a result of their industry structure, experience relatively large positive shocks to employment tend to have lower rates of non-employment other things equal. In contrast, for the Lilien index of sectoral shifts, evidence is found only for a short-run effect on the regional nonemployment rate and even this is below conventional levels of statistical significance. While evidence of a stronger effect might have been expected, the sign of the estimated relationship is at least consistent with the findings from the equations for the regional unemployment rate and the rate of employment growth.

The evidence on the effects of specialisation or diversity in a region's industry-employment mix indicates that a greater or rising degree of specialisation leads to a lower rate of non-employment - evidence which is consistent with the findings from the analysis of regional rates of employment growth rather than the rate of unemployment. When the effects of the individual components of Risk are studied in column (2) the evidence indicates that in the

\footnotetext{
aged over 50 and, alternatively, the proportion of workers aged over 55. However, while the results for the other variables in the equation were largely unaffected, the coefficients for these age variables turned out to be implausibly signed.

${ }^{27}$ It was noted in section 2 above that due to the way in which the figures are constructed the data used for this analysis give a misleading impression of the rate of non-employment in London. However, as long as commuting patterns remain relatively stable over time, the effects of the distortion created by commuting from outside the region should be absorbed by the regional fixed effects that are included in the regression model.
} 
long-run it is the within-industry variance of shocks that matters rather than the cross-industry covariance of shocks, though there is a statistically significant negative effect from the two year change (i.e. the second difference) in the latter variable in the short-run. Finally, the findings for the two demographic variables indicate that, other things equal, the rate of non-employment is lower in regions with a relatively high percentage of males in the working age population, and lower too in regions with a relatively high percentage of members of the population of working age aged under $25 .^{28}$ The latter may seem a somewhat surprising result given the tendency towards higher rates of participation in postcompulsory education in the United Kingdom in recent years but may reflect the effect of relatively high rates of employment amongst young workers when they do eventually enter the labour market. ${ }^{29}$

In summary, the evidence from the three pieces of analysis above indicates that industry structure has statistically significant effects on regional labour market performance. Amongst the explanatory variables we use to examine the effects of industry structure, the evidence is most consistent in the case of the variable Shock, which captures the regional impact of industry-wide employment shocks. The impact of these shocks differs between regions because of regional differences in the industry composition of employment. The findings for this variable indicate that positive shocks to industry employment interpreted here as resulting from shocks to labour demand - lead to a faster rate of employment growth, a lower unemployment rate and a lower rate of non-

\footnotetext{
${ }^{28}$ Note, however, that the variable for the percentage of males in the population of working age is omitted on grounds of statistical insignificance from the equation reported in the third column and has a coefficient that is not quite significant in column (2).

${ }^{29}$ In contrast to this finding, Erdem and Glyn (2001) note the relatively high rate of nonemployment among 16-24 year olds in the UK, in particular among those with low educational qualifications.
} 
employment. Elsewhere, the evidence for industry structure effects on regional labour market performance is a little more mixed. Evidence is found which shows that regions that are subject to a greater degree of structural change, reflected in a higher variance of employment growth across industries, may as a result experience higher rates of unemployment and, in the short-run at least, lower rates of employment growth and a higher rate of non-employment than other regions. Finally there is evidence that regions that have a high and increasing degree of specialisation in their industry-employment mix may experience a faster rate of employment growth and a lower rate of nonemployment. The most likely explanation for this result is that it reflects the effects of industry-specific knowledge spillovers between firms that share a common regional location. ${ }^{30}$

How Important Are the Effects of Industry Structure on Regional Labour Market Performance?

As an indication of the quantitative significance of the effect that differences in industry structure may have on regional labour market performance we can use the results from Table 9 to gauge the effect of changes in industry structure on the impact of industry employment shocks on the regional rate of unemployment. As an example, we consider the case of the North East of England, a region that is often perceived to have been particularly

\footnotetext{
${ }^{30}$ In further, unreported, work we experimented with including the controls for demographic effects, PMale and PYoung, in equations for regional rates of employment growth and the rate of unemployment. Data on the two demographic variables is unavailable for Northern Ireland, however, hence the sample for these experiments was restricted to data from the regions of Great Britain. The results indicate that the proportion of young workers in the population of working age has a positive short-run effect on the rate of employment growth and a negative short-run effect on the regional rate of unemployment. The results are therefore broadly consistent with the findings reported above for the effects of this variable on the rate of non-employment. The proportion of males in the population of working age appears to have no effect. The results for
} 
disadvantaged by the effects of structural change. To examine the effect of changes in industrial structure on the unemployment rate in this region we can compute the value of Shock that would have prevailed in the region if the share of employment in each of our 30 industries had remained constant at its 1975 value. The results of this exercise indicate that over the five years from 19962000 the value of Shock would on average have been 0.251 greater in this region had industry shares remained at their 1975 values (i.e. the positive shock to employment would have been 0.251 percentage points higher). Multiplying this figure by the value of the long-run coefficient for Shock obtained from column (1) of Table 9 (i.e., -0.262) gives a value of $-0.07 .{ }^{31}$ The implication is that by the beginning of the $21^{\text {st }}$ Century, once the dynamic effects had been allowed to work through, changes to industry employment shares will have resulted in the unemployment rate in the North East being around 7 percent (note, not 7 percentage points) higher than it would have been had industry employment shares remained at their 1975 values. In the context of a regional unemployment rate that in the period $2000-03$ averaged around 8.3 percent this effect seems relatively small. The impact of structural change on the unemployment rate in the North East appears rather larger once account is taken of changes in the value of the Lilien index. If we compare the average value of the Lilien index for the North East in the period 1996-2001 with its average value in 1975-80 then performing a similar exercise as that for the variable Shock, again using the estimates from column (1) of Table 9, we find that the increase in the value of the Lilien index leads to an increase in the region's unemployment rate of 14

the effects of the other variables were broadly unaffected by the inclusion of these terms. The detailed results are available on request from the author.

${ }^{31}$ This is rounded up slightly. The long-run coefficients from columns (2) and (3) are -0.287 and -0.248 , respectively, which produce effects of a similar order of magnitude. 
percent in the long-run. ${ }^{32}$ Overall, however, the effect of changes in industry structure on the evolution of unemployment in the North East region seems relatively small. ${ }^{33}$

To what extent to differences in industry structure appear to be able to account for the disparities in unemployment performance across regions? Again, the figures suggest that the effects in fact are not particularly large. The data on the variable Shock indicate that in the second half of the 1990s, for example, differences in industry structure meant that industry employment shocks actually had a more favourable impact on the unemployment rate in the North East than in the South East. In contrast, the higher value of the Lilien index in the North East is estimated to raise the unemployment rate in this region by around 14 percent relative to that in the South East but even this effect seems relatively small when set against an average unemployment rate differential of nearly 6 percentage points between the two regions during the period 2000-03.

\section{Summary and Conclusions}

In this paper, we have attempted to gauge the extent of structural change and changes in the degree of employment specialisation within regions of the United Kingdom and examine their effects on regional labour market performance. We have analysed the effects of structural change on regional labour market performance by using information on industry employment shares to construct a measure of the regional impact of shocks to aggregate industry employment and by calculating values for each region of the index of sectoral

\footnotetext{
${ }^{32}$ For the North East, the increase in the value of the Lilien index in the 1990s may, in particular, reflect the effects of employment decline in the coal industry.
} 
shifts developed by Lilien (1982). The evidence from the latter indicates that over the period from 1972-2001 the incidence of sectoral shifts - a measure of the pace of structural change - was highest in the North East of England, a region that is often perceived has having suffered from the effects of structural change. In contrast, the pace of structural change was lowest in the South East.

Measures of specialisation and/or diversity in regional employment have been constructed, based on the Coefficient of Absolute Regional Specialisation $(C A R S)$, and a measure of a region's exposure to the risk of labour demand shocks, due to Neumann and Topel (1991). The evidence from these measures indicates that since the 1970 s employment in all regions has become increasingly specialised within a relatively narrow range of industries, while changes in the structure of employment have for most regions led to a modest decline in exposure to the risk of labour demand shocks (with a much steeper decline in the North East of England).

The results from panel data regression models in which these various measures are used as explanatory variables indicate that differences between regions in the industry structure of employment have statistically significant effects on regional labour market performance. In particular, differences in industry structure give rise to asymmetries between regions in the effects of aggregate industry employment shocks, which have significant effects on regional unemployment rates, non-employment rates and the rate of regional employment growth.

\footnotetext{
${ }^{33}$ In these calculations, we have ignored the effect of the insignificant variable Risk. However, taking the reported coefficient for Risk at face value, changes in the value of this variable would have contributed to a reduction in the unemployment rate in the North East.
} 
However, while industry structure effects may be statistically significant, the evidence from this analysis indicates that quantitatively they are of relatively minor importance in accounting either for variations in regional labour market performance over time or for performance disparities between regions. In terms of the econometric models reported in this paper, it seems that most of the performance disparities between regions can only be accounted for by unobserved regional 'fixed effects', the sources of which remain to be explained. During the past two decades, a large body of literature has developed that has both highlighted the existence of and sought to find explanations for a trend decline in the relative demand for unskilled labour in the UK and other developed market economies. ${ }^{34}$ Little attempt has been made to examine the regional implications of this trend but there are reasons to believe that this could be a significant factor in accounting for the observed persistent differentials in regional labour market performance. In particular, Bradley and Taylor (1996) and Green and Owen (2006) have shown that the less prosperous regions in the UK tend to have higher proportions of individuals with relatively low educational qualifications. It is well known that such individuals tend to experience relatively high rates of unemployment and economic inactivity (see Erdem and Glyn, 2001). While skill differentials between regions will to some extent be reflected in differences in industry structure and the incidence of structural change (Bernard et al, 2005), the correspondence between the skill and industry composition of regional employment is unlikely to be unique. Unfortunately, data limitations preclude an investigation of this issue in the current study.

${ }^{34}$ See, for example, Machin (1996) and Berman et al (1994). 
The findings of this study indicate that the convergence that has taken place over the past thirty years in the industry structures of different regions in the United Kingdom has had only a limited effect in reducing disparities in regional labour market performance. For public policy, the implication is that attempts to stimulate further convergence - e.g. through subsidies to the creation of service sector jobs in areas of traditional manufacturing employment - are unlikely, in themselves, to be of much benefit in tackling these regional disparities. The benefits of such measures are more likely to be felt in terms of their direct job creation effects, which when combined with New Deal-type schemes aimed at improving the employability of workers in under-performing regions, are likely to prove a more effective remedy for tackling disparities in the labour market performance of UK regions. 


\section{Acknowledgement}

* I am grateful to Katerina Homenidou of Cambridge Econometrics for supplying the data on regional employment by industry used in this study, and to the Royal Economic Society Small Academic Expenses Fund for a grant to cover the cost of purchasing the data. My thanks are due also to Phil Murphy, Ian Stone, participants at a Departmental workshop in Durham and the 2006 WPEG conference in Canterbury, and most of all to an anonymous referee, for their helpful comments on previous drafts. I retain responsibility for any remaining errors in the analysis, interpretation or presentation. 
Table 1. Regional Employment Structure, 1975-2001

\begin{tabular}{|c|c|c|c|c|c|c|c|c|c|c|c|c|c|}
\hline & $\mathrm{NE}$ & NW & YH & EM & WM & EA & LON & SE & SW & WA & $\mathrm{SC}$ & NI & UK \\
\hline Agriculture & 1.8 & 1.5 & 2.7 & 3.4 & 1.9 & 4.6 & 0.1 & 2.9 & 4.9 & 6.2 & 3.9 & 7.1 & 2.7 \\
\hline $\begin{array}{l}\text { Mining } \quad \& \\
\text { Quarrying }\end{array}$ & 4.4 & 0.5 & 3.7 & 4.0 & 1.0 & 0.3 & 0.1 & 0.8 & 0.6 & 4.3 & 1.7 & 0.4 & 1.5 \\
\hline $\begin{array}{l}\text { Electricity, } \\
\text { Gas, etc. }\end{array}$ & 1.0 & 1.8 & 1.2 & 1.3 & 1.3 & 1.2 & 1.2 & 1.1 & 1.2 & 1.2 & 0.8 & 1.5 & 1.2 \\
\hline Construction & 8.4 & 6.2 & 6.6 & 6.5 & 6.4 & 7.9 & 5.9 & 6.9 & 7.4 & 7.5 & 8.5 & 8.4 & 6.9 \\
\hline Manufacturing & 30.4 & 32.7 & 31.6 & 33.9 & 38.7 & 27.3 & 18.8 & 23.0 & 22.9 & 25.7 & 26.1 & 26.7 & 27.6 \\
\hline Services & 53.8 & 57.4 & 54.1 & 51.0 & 50.8 & 58.8 & 73.9 & 65.2 & 63.0 & 55.1 & 59.0 & 55.9 & 60.1 \\
\hline Total (000s) & 1229.5 & 3276.4 & 2290.8 & 1731.0 & 2473.2 & 2041.0 & 4426.4 & 3069.9 & 1882.6 & 1206.7 & 2434.2 & 590.9 & 26652.6 \\
\hline
\end{tabular}

$2001(\%)$

\begin{tabular}{|c|c|c|c|c|c|c|c|c|c|c|c|c|c|}
\hline & $\mathrm{NE}$ & NW & $\mathrm{YH}$ & EM & WM & EA & LON & SE & SW & WA & $\mathrm{SC}$ & NI & UK \\
\hline Agriculture & 1.1 & 0.9 & 1.6 & 1.9 & 1.7 & 2.0 & 0.2 & 1.7 & 2.9 & 2.4 & 2.3 & 4.1 & 1.6 \\
\hline $\begin{array}{l}\text { Mining \& } \\
\text { Quarrying }\end{array}$ & 0.4 & 0.1 & 0.3 & 0.5 & 0.1 & 0.2 & 0.1 & 0.1 & 0.3 & 0.3 & 1.1 & 0.3 & 0.3 \\
\hline $\begin{array}{l}\text { Electricity, } \\
\text { Gas, etc. }\end{array}$ & 0.8 & 0.2 & 0.3 & 0.4 & 0.6 & 0.6 & 0.1 & 0.3 & 0.4 & 0.4 & 0.5 & 0.5 & 0.4 \\
\hline Construction & 6.0 & 6.3 & 6.6 & 7.1 & 5.5 & 7.7 & 5.0 & 6.8 & 6.5 & 7.0 & 6.7 & 6.9 & 6.4 \\
\hline Manufacturing & 17.2 & 16.1 & 16.9 & 19.7 & 19.9 & 13.7 & 6.9 & 11.2 & 13.1 & 16.7 & 12.4 & 14.1 & 13.8 \\
\hline Services & 74.6 & 76.4 & 74.3 & 70.4 & 72.1 & 75.9 & 87.8 & 79.9 & 76.8 & 73.2 & 76.9 & 74.2 & 77.5 \\
\hline Total (000s) & 1038.2 & 3156.1 & 2323.7 & 1976.0 & 2541.7 & 2610.2 & 4576.0 & 4198.3 & 2449.5 & 1231.4 & 2476.1 & 750.5 & 29327.7 \\
\hline
\end{tabular}




\section{Table 1. continued}

\begin{tabular}{|c|c|c|c|c|c|c|c|c|c|c|c|c|c|}
\hline & $\mathrm{NE}$ & NW & $\mathrm{YH}$ & EM & WM & EA & $\mathrm{LON}$ & SE & SW & WA & $\mathrm{SC}$ & NI & UK \\
\hline Agriculture & -0.7 & -0.6 & -1.1 & -1.6 & -0.2 & -2.6 & 0.1 & -1.2 & -2.0 & -3.8 & -1.6 & -3.0 & -1.1 \\
\hline $\begin{array}{l}\text { Mining } \\
\text { Quarrying }\end{array}$ & -4.0 & -0.4 & -3.4 & -3.5 & -0.9 & -0.1 & 0.0 & -0.7 & -0.3 & -4.0 & -0.6 & -0.1 & -1.2 \\
\hline $\begin{array}{l}\text { Electricity, } \\
\text { Gas, etc. }\end{array}$ & -0.2 & -1.6 & -0.9 & -0.9 & -0.7 & -0.6 & -1.1 & -0.8 & -0.8 & -0.8 & -0.3 & -1.0 & -0.8 \\
\hline Construction & -2.4 & 0.1 & 0.0 & 0.6 & -0.9 & -0.2 & -0.9 & -0.1 & -0.9 & -0.5 & -1.8 & -1.5 & -0.5 \\
\hline Manufacturing & -13.4 & -16.6 & -14.7 & -14.2 & -18.8 & -13.6 & -11.9 & -11.8 & -9.8 & -9.0 & -13.7 & -12.6 & -13.8 \\
\hline Services & 20.6 & 19.0 & 20.2 & 19.4 & 21.3 & 17.1 & 13.9 & 14.7 & 13.8 & 18.1 & 17.9 & 18.3 & 17.4 \\
\hline Total (000s) & -191.3 & -120.3 & 32.9 & 245.0 & 68.5 & 569.2 & 149.6 & 1128.4 & 566.9 & 24.7 & 41.9 & 159.6 & 2675.1 \\
\hline
\end{tabular}

Notes: $\mathrm{NE}=$ North East, $\mathrm{NW}=$ North West, $\mathrm{YH}=$ Yorkshire and Humberside, $\mathrm{EM}=$ East Midlands, WM $=$ West Midlands, EA $=$ East, LON $=$ London, SE $=$ South East, $\mathrm{SW}=$ South West, WA = Wales, $\mathrm{SC}=$ Scotland, NI = Northern Ireland, UK = United Kingdom .

Source of data: author's calculations based on data supplied by Cambridge Econometrics. 
Table 2. Coefficient of Regional Specialisation

\begin{tabular}{|c|c|c|c|c|c|c|c|c|c|c|c|c|}
\hline & $\mathrm{NE}$ & NW & $\mathrm{YH}$ & EM & WM & EA & LON & $\mathrm{SE}$ & SW & WA & $\mathrm{SC}$ & NI \\
\hline \multicolumn{13}{|l|}{ Average value } \\
\hline $1975-2001$ & 9.6 & 6.0 & 7.6 & 10.8 & 11.8 & 6.8 & 15.4 & 6.0 & 8.1 & 10.3 & 6.5 & 20.5 \\
\hline $1975-84$ & 11.1 & 7.1 & 9.6 & 12.5 & 14.2 & 8.6 & 14.3 & 6.9 & 9.4 & 11.6 & 6.3 & 22.5 \\
\hline $1985-94$ & 8.0 & 5.3 & 6.7 & 10.2 & 10.6 & 5.8 & 15.0 & 5.3 & 7.6 & 9.1 & 6.1 & 20.6 \\
\hline $1995-2001$ & 9.7 & 5.4 & 6.2 & 9.1 & 10.2 & 5.5 & 17.6 & 5.7 & 6.9 & 10.4 & 7.5 & 17.3 \\
\hline Change 1975-2001 & -1.8 & -3.0 & -4.4 & -4.0 & -6.6 & -3.7 & 2.9 & -1.8 & -3.1 & -2.3 & 1.7 & -7.2 \\
\hline
\end{tabular}

See notes to Table 1. 
Table 3. Regional Impact of Aggregate Industry Employment Shocks

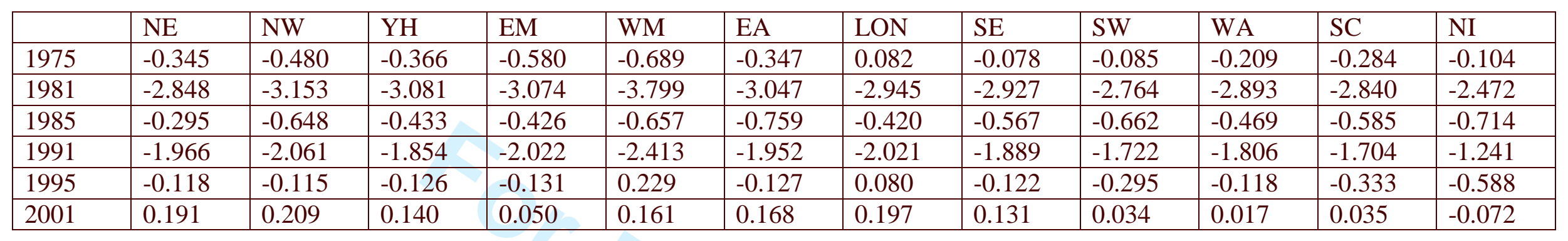

Note: The data show the value of Shock $_{r t}$, which is constructed as described in equations (1) and (2) in the text. 
Table 4. Lilien Index

Average values

\begin{tabular}{lllllllllllll}
\hline & NE & NW & YH & EM & WM & EA & LON & SE & SW & WA & SC & NI \\
\hline $1975-2001$ & 0.644 & 0.411 & 0.504 & 0.509 & 0.487 & 0.424 & 0.415 & 0.383 & 0.424 & 0.603 & 0.472 & 0.440 \\
$1975-84$ & 0.493 & 0.373 & 0.414 & 0.402 & 0.408 & 0.386 & 0.305 & 0.334 & 0.361 & 0.534 & 0.457 & 0.510 \\
$1985-94$ & 0.703 & 0.416 & 0.536 & 0.562 & 0.471 & 0.444 & 0.484 & 0.416 & 0.470 & 0.643 & 0.449 & 0.397 \\
$1995-2001$ & 0.773 & 0.460 & 0.586 & 0.587 & 0.620 & 0.449 & 0.475 & 0.406 & 0.446 & 0.646 & 0.524 & 0.403 \\
\hline
\end{tabular}

See notes to Table 1 . 
Table 5. Estimated Regional Employment Risk

Average values

\begin{tabular}{lllllllllllll}
\hline & NE & NW & YH & EM & WM & EA & LON & SE & SW & WA & SC & NI \\
\hline $1975-2001$ & 4.154 & 2.520 & 2.184 & 1.902 & 2.657 & 2.002 & 2.689 & 2.900 & 2.166 & 4.145 & 1.623 & 1.501 \\
$1975-84$ & 5.437 & 2.606 & 2.338 & 1.917 & 2.907 & 2.041 & 2.829 & 3.229 & 2.167 & 4.211 & 1.711 & 1.591 \\
$1985-94$ & 3.584 & 2.494 & 2.133 & 1.908 & 2.583 & 1.992 & 2.654 & 2.753 & 2.199 & 4.148 & 1.594 & 1.461 \\
$1995-2001$ & 3.135 & 2.433 & 2.038 & 1.871 & 2.407 & 1.960 & 2.541 & 2.639 & 2.120 & 4.046 & 1.538 & 1.429 \\
\hline
\end{tabular}

Notes: estimated values are variances of log employment disturbances, Risk $k_{r t}$, calculated as described in the text. 
Table 6. Coefficient of Absolute Regional Specialisation (CARS)

Average values

\begin{tabular}{lllllllllllll}
\hline & NE & NW & YH & EM & WM & EA & LON & SE & SW & WA & SC & NI \\
\hline $1975-2001$ & 113.5 & 110.5 & 108.2 & 103.1 & 105.9 & 112.9 & 139.0 & 122.9 & 114.9 & 113.2 & 115.3 & 138.0 \\
$1975-84$ & 95.6 & 95.1 & 93.0 & 89.2 & 95.9 & 2.041 & 121.6 & 108.3 & 104.1 & 100.0 & 101.3 & 131.1 \\
$1985-94$ & 119.3 & 113.1 & 111.8 & 105.3 & 106.9 & 1.992 & 140.9 & 125.2 & 116.4 & 116.1 & 118.9 & 140.1 \\
$1995-2001$ & 131.0 & 128.8 & 124.9 & 119.8 & 118.9 & 1.960 & 161.2 & 140.5 & 128.1 & 128.0 & 130.0 & 143.6 \\
\hline
\end{tabular}

See notes to Table 1 . 
Table 7. Panel Unit Root Tests

\begin{tabular}{||l|l||}
\hline \hline Variable & CIPS \\
\hline$\Delta \ln e$ & $-2.74^{*}$ \\
\hline $\ln u$ & -1.82 \\
\hline $\ln$ ner & -1.82 \\
\hline Shock & $-4.35^{*}$ \\
\hline Lilien & $-2.93^{*}$ \\
\hline Risk & -2.00 \\
\hline CARS & -2.15 \\
\hline
\end{tabular}

$\underline{\text { Note }}$

The CIPS test is an extension to the IPS test developed for testing for unit roots in panel data by Im, Pesaran and Shin (2003) and is based on estimating regression equations of the form

$\Delta y_{t}=\alpha+\beta_{i} \Delta y_{t-i}-\gamma y_{t-1}+\phi_{i} \Delta \bar{y}_{t+1-i}+\theta \bar{y}_{t-1}+\varepsilon_{t}$ for each of the cross-section units in the panel,

where $\mathrm{y}$ is the variable of interest and $\bar{y}$ is its cross-sectional average value. The inclusion of this term is to take account of any cross-sectional dependence between the individual time-series. The number of lagged difference terms included in the test regression is determined by the need to ensure that the disturbances of the equation are free from serial correlation. The test provides a test of the null hypothesis of a unit root against the alternative of stationarity. The test statistic, which is akin to the ADF test statistic used to test for unit roots in a standard time-series setting, is calculated by taking the average value of the 't-ratio' for the estimated value of $\gamma$ in the individual time-series regressions. Critical values of the statistic for various values of $\mathrm{N}$, the number of cross-section units, and $\mathrm{T}$, the number of time-series observations, are tabulated in Pesaran (2005).

For all variables except ln ner, the test regressions are estimated using data for the period 1977-2001 for each of the 12 UK regions. For ln ner, the sample period is 1983-2001 and data is available only for the 11 regions of Great Britain, with Northern Ireland excluded. An asterisk denotes that the test statistic is significant at the $5 \%$ level. 
Table 8. Panel Data Regressions for Regional Employment Growth, 1983-2001.

The dependent variable is $\Delta \ln e_{r t}$

\begin{tabular}{|c|c|c|c|}
\hline & (1) & (2) & (3) \\
\hline Shock $_{r t}$ & $\begin{array}{l}0.009 * * \\
(2.08)\end{array}$ & $\begin{array}{l}0.010 * * \\
(2.43)\end{array}$ & $\begin{array}{l}0.010 * * \\
(2.24)\end{array}$ \\
\hline Shock $_{r t-1}$ & $\begin{array}{l}0.007 * * \\
(2.32)\end{array}$ & $\begin{array}{l}0.008 * * \\
(2.56)\end{array}$ & $\begin{array}{l}0.006^{* *} * \\
(2.32)\end{array}$ \\
\hline Shock $_{r t-2}$ & $\begin{array}{l}-0.006^{*} \\
(1.69)\end{array}$ & $\begin{array}{l}-0.006^{*} \\
(1.69)\end{array}$ & $\begin{array}{l}-0.007 * * \\
(2.01)\end{array}$ \\
\hline$\Delta R i s k_{r t}$ & $\begin{array}{l}0.086^{* * *} \\
(2.45)\end{array}$ & & \\
\hline $\operatorname{Risk}_{r t-2}$ & $\begin{array}{l}0.013^{* *} \\
(2.26)\end{array}$ & & \\
\hline$\Delta R i s k V_{r t}$ & & $\begin{array}{l}0.081 * * * \\
(4.08)\end{array}$ & \\
\hline$\Delta \operatorname{Risk}_{r t-1}$ & & $\begin{array}{l}-0.069 * * * \\
(3.85)\end{array}$ & \\
\hline Risk $V_{r t-2}$ & & $\begin{array}{l}0.008 \\
(1.64)\end{array}$ & \\
\hline$\Delta R i s k C_{r t}$ & & $\begin{array}{l}0.125 * * * \\
(2.86)\end{array}$ & \\
\hline$\Delta R i s k C_{r t-1}$ & & $\begin{array}{l}0.091 * * \\
(2.40)\end{array}$ & \\
\hline$R i s k C_{r t-2}$ & & $\begin{array}{l}0.019 * * \\
(2.02)\end{array}$ & \\
\hline$\Delta C A R S_{r t} \times 10^{-2}$ & & & $\begin{array}{l}0.083 \\
(1.59)\end{array}$ \\
\hline$\Delta$ Lilien $_{r t}$ & $\begin{array}{l}-0.010 \\
(1.48)\end{array}$ & $\begin{array}{l}-0.008 \\
(1.39)\end{array}$ & $\begin{array}{l}-0.010^{*} \\
(1.71)\end{array}$ \\
\hline$\Delta \ln P D_{e n} n_{t-1}$ & $\begin{array}{l}1.397 * * * \\
(5.40)\end{array}$ & $\begin{array}{l}1.236 * * * \\
(4.36)\end{array}$ & $\begin{array}{l}1.527 \text { *** } \\
(6.14)\end{array}$ \\
\hline Constant & $\begin{array}{l}-0.054 * * * \\
(3.11)\end{array}$ & $\begin{array}{l}-0.053 \text { *** } \\
(3.82)\end{array}$ & $\begin{array}{l}-0.018 \\
(1.58)\end{array}$ \\
\hline $\mathrm{R}^{2}$ & 0.725 & 0.741 & 0.711 \\
\hline $\mathrm{m}_{1}$ & -0.08 & -0.48 & -0.27 \\
\hline $\mathrm{N}$ & 228 & 228 & 228 \\
\hline
\end{tabular}

Notes: Estimation is by Least Squares Dummy Variables, with an allowance for regional fixed effects. Absolute t-ratios based on heteroscedasticity-robust standard errors are given in parenthesis. Asterisks denote that the coefficient is statistically significant at the $1 \%(* * *), 5 \%(* *)$ or $10 \%(*)$ level on a two-sided test. A full set of time dummies is included in each equation. $\mathrm{m}_{1}$ denotes a test statistic for first order serial correlation in the equation residuals, which has an asymptotic standard normal distribution. 
Table 9. Panel Data Regressions of Regional Unemployment Rates, 1978-2001.

The dependent variable is $\ln u_{r t}$

\begin{tabular}{|c|c|c|c|}
\hline & (1) & (2) & (3) \\
\hline $\ln u_{r t-1}$ & $\begin{array}{l}1.252 * * * \\
(47.0)\end{array}$ & $\begin{array}{l}1.240 * * * \\
(57.5)\end{array}$ & $\begin{array}{l}1.252 * * * \\
(49.1)\end{array}$ \\
\hline $\ln u_{r t-2}$ & $\begin{array}{l}-0.557 * * * \\
(15.9)\end{array}$ & $\begin{array}{l}-0.543^{* * * *} \\
(13.8)\end{array}$ & $\begin{array}{l}-0.558 * * * \\
(14.9)\end{array}$ \\
\hline Shock $_{r t}$ & $\begin{array}{l}-0.128^{* * *} \\
(8.80)\end{array}$ & $\begin{array}{l}-0.133^{* * * *} \\
(9.36)\end{array}$ & $\begin{array}{l}-0.125^{* * *} \\
(7.91)\end{array}$ \\
\hline Shock $_{r t-2}$ & $\begin{array}{l}0.048 * * \\
(3.96)\end{array}$ & $\begin{array}{l}0.046^{* * * *} \\
(4.23)\end{array}$ & $\begin{array}{l}0.049 * * * \\
(3.74)\end{array}$ \\
\hline Lilien $_{r t-2}$ & $\begin{array}{l}0.112 * * * \\
(3.16)\end{array}$ & $\begin{array}{l}0.098 * * * \\
(2.72)\end{array}$ & $\begin{array}{l}0.105^{* * * *} \\
(2.89)\end{array}$ \\
\hline Risk $_{r t-2}$ & $\begin{array}{l}0.026 \\
(1.39)\end{array}$ & & \\
\hline $\operatorname{Risk} V_{r t}$ & & $\begin{array}{l}0.049 \\
(0.92)\end{array}$ & \\
\hline RiskV $V_{r t-2}$ & & $\begin{array}{l}-0.022 \\
(0.58)\end{array}$ & \\
\hline $\operatorname{RiskC}_{r t}$ & & $\begin{array}{l}-0.354 * * \\
(2.50)\end{array}$ & \\
\hline$R i s k C_{r t-2}$ & & $\begin{array}{l}0.199 \\
(1.48)\end{array}$ & \\
\hline$\Delta C A R S_{r t-1} \times 10^{-2}$ & & & $\begin{array}{l}0.290 \\
(1.08)\end{array}$ \\
\hline Constant & $\begin{array}{l}0.267 * * * \\
(8.58)\end{array}$ & $\begin{array}{l}0.261 * * * \\
(8.40)\end{array}$ & $\begin{array}{l}0.269 * * * \\
(7.86)\end{array}$ \\
\hline s.e. & 0.078 & 0.077 & 0.078 \\
\hline $\mathrm{m}_{1}$ & $-3.00^{++}$ & $-3.01^{++}$ & $-2.99^{++}$ \\
\hline $\mathrm{m}_{2}$ & -0.61 & -0.34 & -0.59 \\
\hline $\mathrm{N}$ & 288 & 288 & 288 \\
\hline
\end{tabular}

Notes: Estimates are obtained using the GMM in differences estimator of Arellano and Bond (1991). Absolute t-ratios based on heteroscedasticity-robust standard errors are given in parenthesis. Asterisks denote that the coefficient is statistically significant at the $1 \%(* * *), 5 \%(* *)$ or $10 \%(*)$ level on a two-sided test. A full set of time dummies is included in each equation. $\mathrm{m}_{1}$ and $\mathrm{m}_{2}$ denote test statistics for first and second order serial correlation, respectively, in the residuals of the equation. Each has an asymptotic standard normal distribution. A plus mark ${ }^{+}\left({ }^{++}\right)$indicates that the test statistic is significant at the $5 \%(1 \%)$ level. 
Table 10. Panel Data Regressions of Regional Non-Employment Rates, 19832001.

The dependent variable is $\ln n e r_{r t}$

\begin{tabular}{|c|c|c|c|}
\hline & (1) & $(2)$ & (3) \\
\hline $\ln n e r_{t-1}$ & $\begin{array}{l}0.751 * * * \\
(32.1)\end{array}$ & $\begin{array}{l}0.765 * * * \\
(30.4)\end{array}$ & $\begin{array}{l}0.785 * * * \\
(31.0)\end{array}$ \\
\hline Shock $_{r t-1}$ & $\begin{array}{l}-0.052^{* * * *} \\
(3.03)\end{array}$ & $\begin{array}{l}-0.046 * * \\
(2.32)\end{array}$ & $\begin{array}{l}-0.063 * * * \\
(2.62)\end{array}$ \\
\hline Shock $_{r t-2}$ & & & $\begin{array}{l}-0.027^{*} \\
(1.75)\end{array}$ \\
\hline$\Delta$ Lilien $_{r t}$ & & & $\begin{array}{l}0.028 \\
(1.30)\end{array}$ \\
\hline$\Delta_{2}$ Lilien $_{r t}$ & $\begin{array}{l}0.020 \\
(1.61)\end{array}$ & & \\
\hline$\Delta^{2} R i s k_{r t}$ & $\begin{array}{l}-0.065^{*} \\
(1.66)\end{array}$ & & \\
\hline$R_{i s k_{r t-2}}$ & $\begin{array}{l}-0.035^{* * * *} \\
(3.12)\end{array}$ & & \\
\hline$\Delta^{2} R i s k V_{r t}$ & & $\begin{array}{l}-0.154 * * \\
(2.03)\end{array}$ & \\
\hline$R i s k V_{r t-2}$ & & $\begin{array}{l}-0.073 \text { *** } \\
(3.75)\end{array}$ & \\
\hline$\Delta_{2} R i s k C_{r t}$ & & $\begin{array}{l}-0.191 * * * \\
(2.85)\end{array}$ & \\
\hline$\Delta C A R S_{r t} \times 10^{-2}$ & & & $\begin{array}{l}-0.747 \\
(1.61)\end{array}$ \\
\hline$[\text { PMale }]_{r t}$ & $\begin{array}{l}-0.068^{*} \\
(1.66)\end{array}$ & $\begin{array}{l}-0.059 \\
(1.48)\end{array}$ & \\
\hline$[\text { PYoung }]_{r t}$ & $\begin{array}{l}-0.085 \\
(1.64)\end{array}$ & $\begin{array}{l}-0.098 * * \\
(2.06)\end{array}$ & $\begin{array}{l}-0.077^{*} \\
(1.69)\end{array}$ \\
\hline Constant & $\begin{array}{l}0.139 * * * \\
(3.69)\end{array}$ & $\begin{array}{l}0.128 * * * \\
(2.85)\end{array}$ & $\begin{array}{l}0.101 * * \\
(2.23)\end{array}$ \\
\hline s.e. & $\begin{array}{c}0.058 \\
210^{+}\end{array}$ & $\begin{array}{l}0.059 \\
214^{+}\end{array}$ & $\begin{array}{l}0.060 \\
200^{+}\end{array}$ \\
\hline $\begin{array}{l}\mathrm{m}_{1} \\
\mathrm{~m}_{2}\end{array}$ & $\begin{array}{l}-2.10^{+} \\
-0.69\end{array}$ & $\begin{array}{l}-2.14^{+} \\
-0.65\end{array}$ & $\begin{array}{l}-2.00^{+} \\
-0.50\end{array}$ \\
\hline $\mathrm{N}$ & 209 & 209 & 209 \\
\hline
\end{tabular}

Notes: Estimates are obtained using the GMM in differences estimator of Arellano and Bond (1991). Absolute t-ratios based on heteroscedasticity-robust standard errors are given in parenthesis. Asterisks denote that the coefficient is statistically significant at the $1 \%(* * *), 5 \%(* *)$ or $10 \%(*)$ level on a two-sided test. A full set of time dummies is included in each equation. $\mathrm{m}_{1}$ and $\mathrm{m}_{2}$ denote test statistics for first and second order serial correlation, respectively, in the residuals of the equation. Each has an asymptotic standard normal distribution. A plus mark ${ }^{+}\left({ }^{++}\right)$indicates that the test statistic is significant at the $5 \%(1 \%)$ level. 
Figure 1. Coefficient of Regional Specialisation

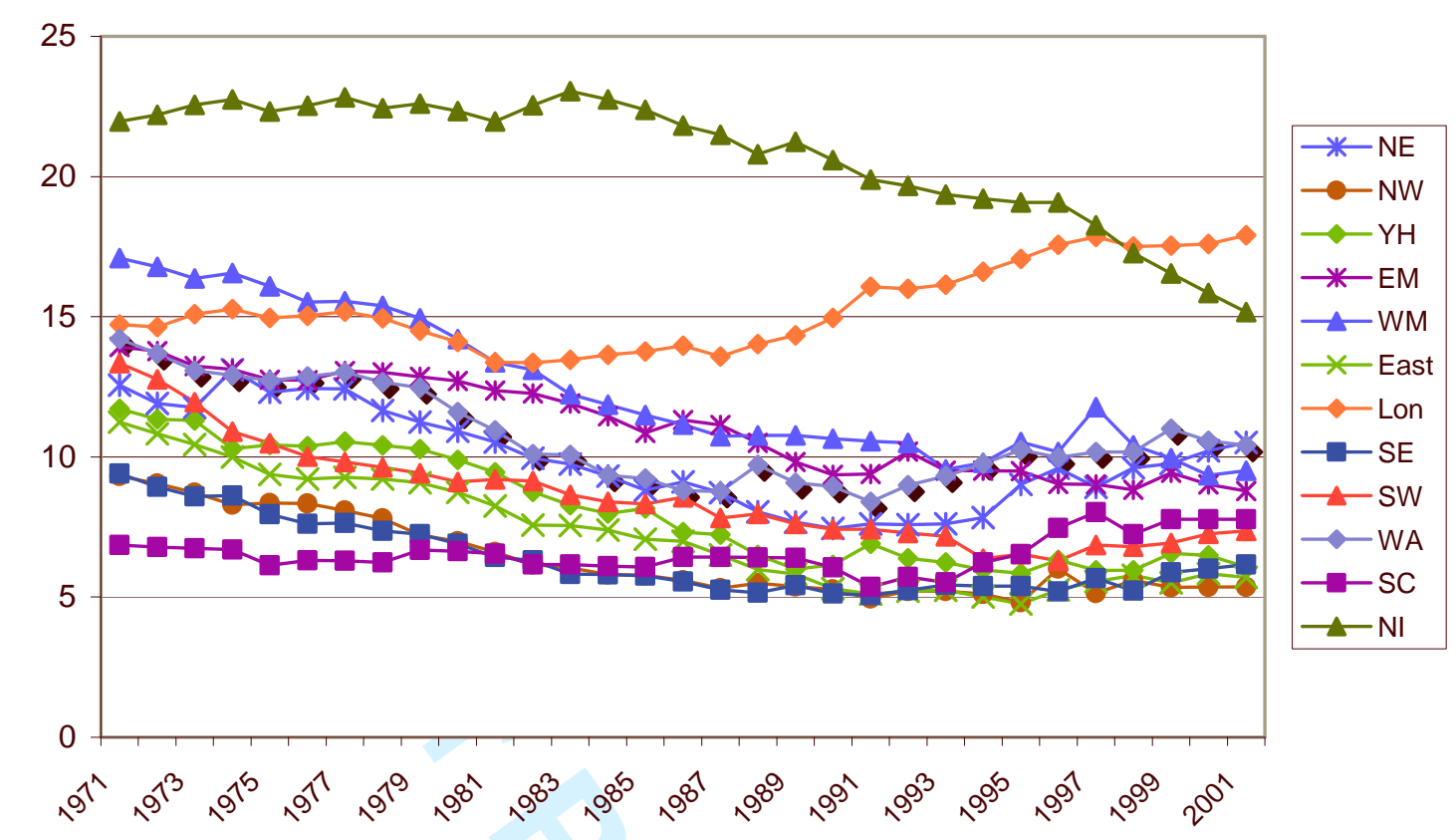

Source: author's calculations based on data from Cambridge Econometrics

Figure 2. Employment in Government Office Regions (1975=100)

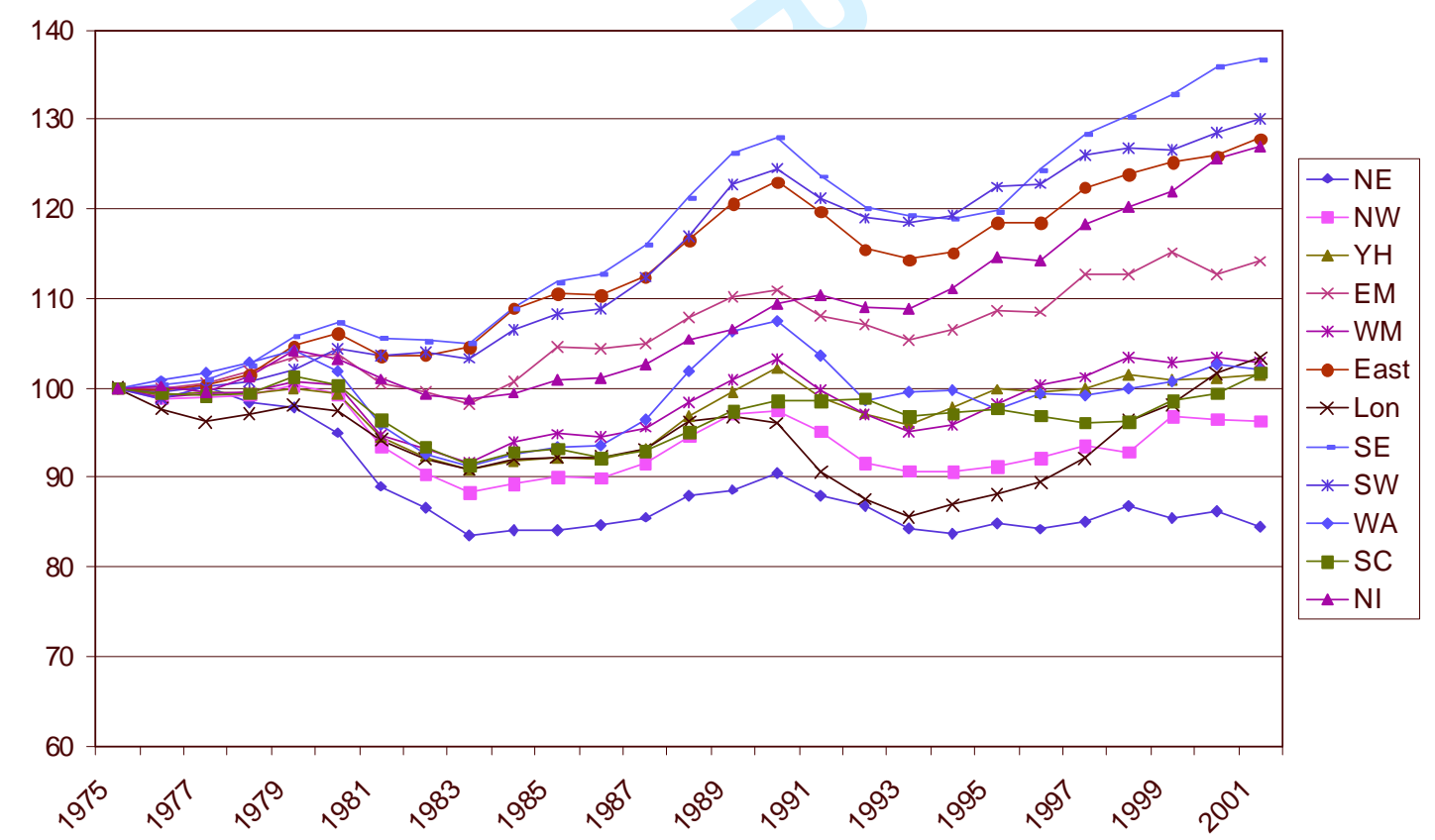

Source: author's calculations based on data from Cambridge Econometrics 
Figure 3. Claimant Count Unemployment Rates, 1975-2003

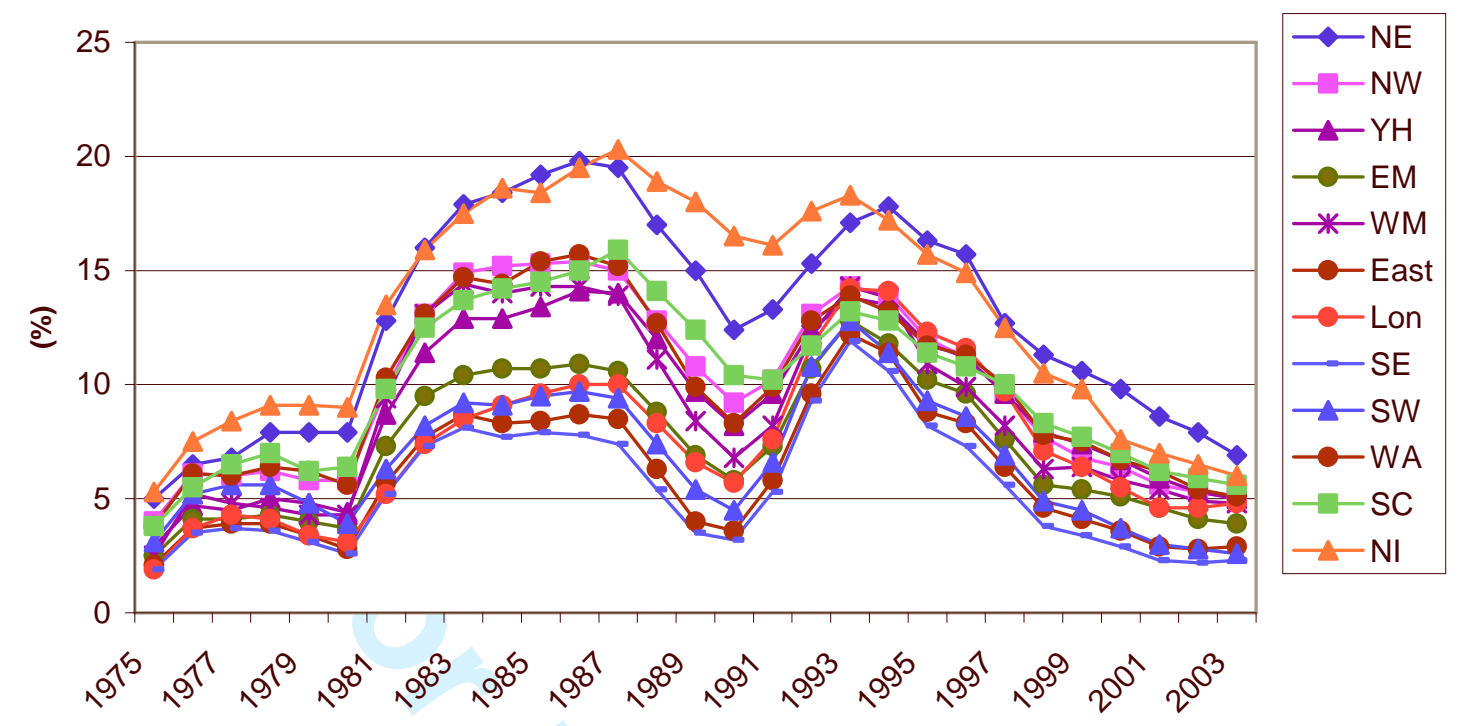

Source: ONS

Figure 4. Rates of Non-employment in UK Government Office Regions

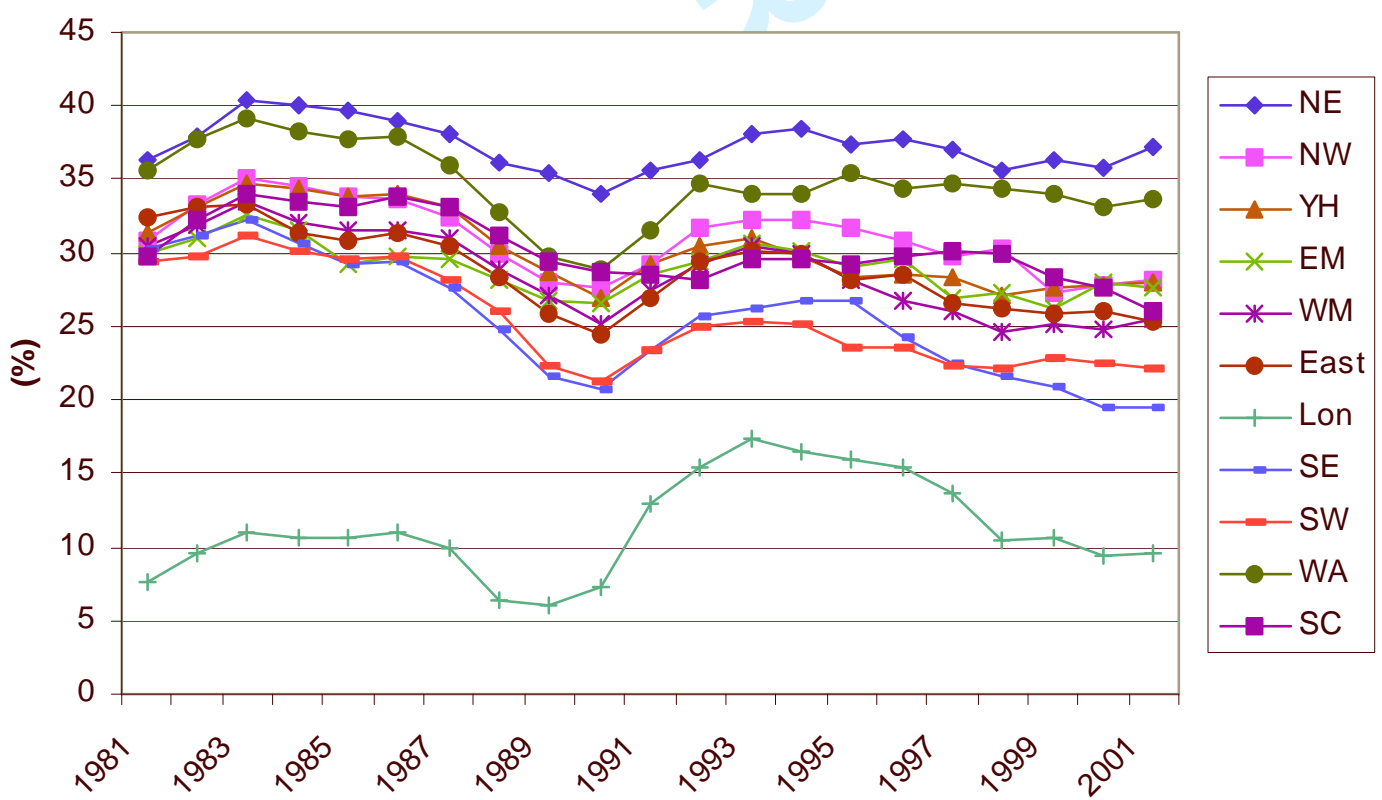

Note: For each region, the non-employment rate in proportionate terms is calculated as one minus the ratio of the number of individuals employed in the region to the size of the population of working age. The resulting figure is then multiplied by 100. The employment data were provided by Cambridge Econometrics, while the figures for the population of working age come from NOMIS. 
Figure 5. Employment Risk

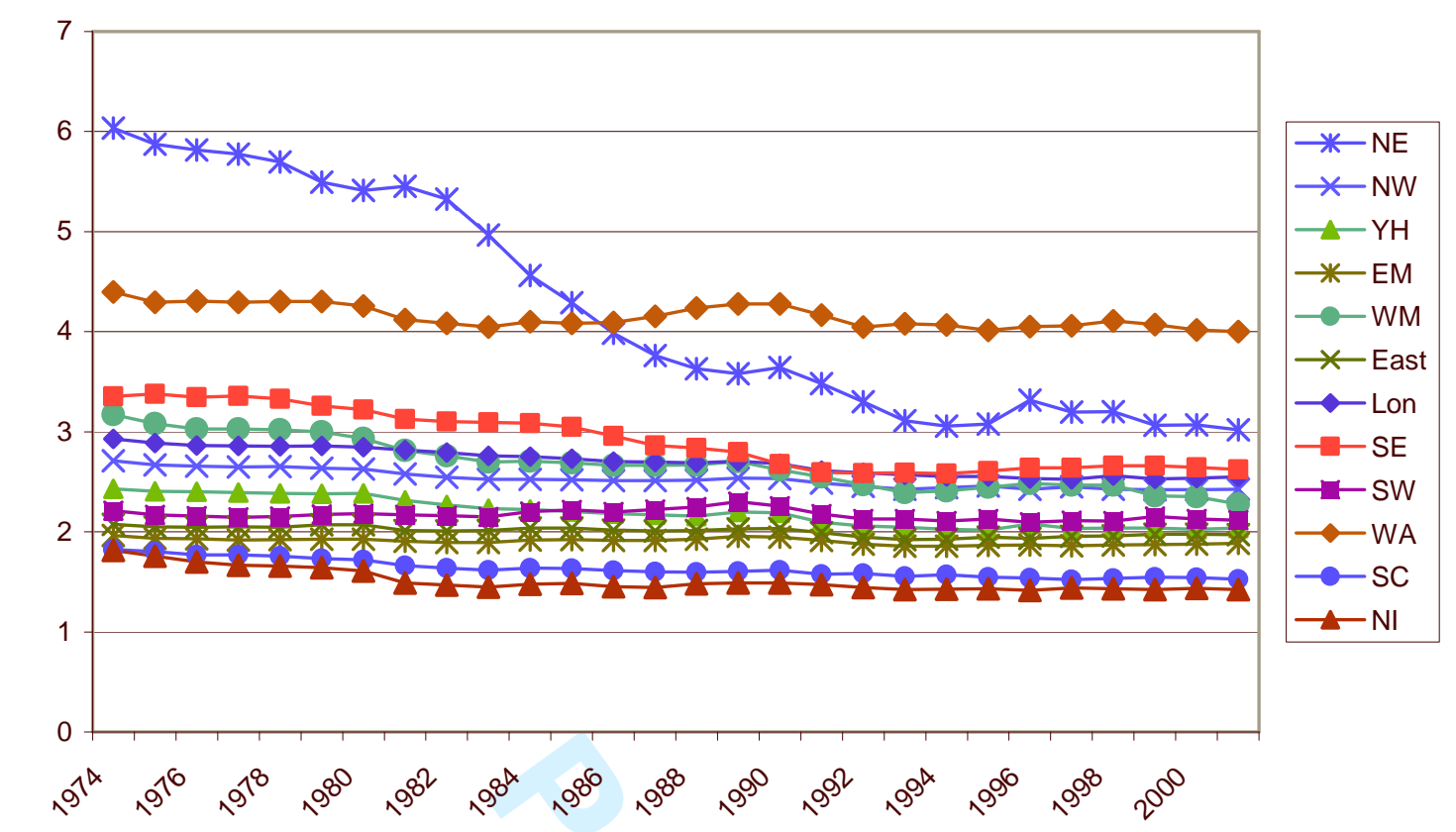

Note: variances of log employment disturbances, Risk, calculated as described in the text. 


\section{Appendix - List of Industries Used in Calculation of the Lilien Index and Employment Specialisation Measures}

1. Agriculture etc

2. Electricity, gas \& water

3. Construction

\section{Mining \& quarrying}

4. Coal

5. Oil \& natural gas etc

6. Other mining

\section{Manufacturing}

7. Food, drink \& tobacco

8. Textiles, clothing \& leather

9. Wood \& wood products

10. Paper, printing \& publishing.

11. Manufactured fuels

12. Chemicals \& man-made fibres

13. Rubber \& plastic products

14. Non-metal mineral products

15. Basic metals \& metal products

16. Mechanical engineering

17. Electronic, electrical and instrument engineering

18. Motor vehicles

19. Other transport equipment

20. Other manufacturing

\section{Services}

21. Retailing

22. Distribution nes

23. Hotels \& catering

24. Transport \& communications

25. Banking \& finance

26. Insurance

27. Other business services

28. Public administration \& defence

29. Education \& health

30. Other services

The employment data is supplied by Cambridge Econometrics. The industry aggregates are based on a mapping of Minimum List Headings under the 1968 Standard Industrial Classification (SIC) on to the Activity Headings under the 1980 SIC and on to Divisions under the 1992 SIC (Wren and Taylor, 1999). 


\section{References}

Abraham, K.G. and L.F. Katz, (1986), 'Cyclical Unemployment: Sectoral Shifts or Aggregate Disturbances?’ Journal of Political Economy, 94, pp. 507-22.

Arellano, M. and Bond, S., (1991), 'Some Tests of Specification for Panel Data: Monte Carlo Evidence and an Application to Employment Equations', Review of Economic Studies, 58, pp. 277-97.

Bacon, R. and Eltis, W., (1976), Britain's Economic Problem: Too Few Producers. Macmillan: London.

Berman, E., Bound, J. and Griliches, Z., (1994), 'Changes in the Demand for Skilled Labour Within U.S. Manufacturing Industries: Evidence from the Annual Survey of Manufacturing', Quarterly Journal of Economics, 109, pp. 367-97.

Bernard, A.B., Redding, S., Schott, P.K., and Simpson, H., (2005), 'Relative Wage Variation and Industry Location in the United Kingdom', Working Paper, Tuck School of Business at Dartmouth.

Blackaby, D. and Murphy, P., (1995), 'Earnings, Unemployment and Britain's North-South Divide: Real or Imaginary?', Oxford Bulletin of Economics and Statistics, 57, pp. 487-512.

Bradley, S. and Taylor, J., (1996), 'Human Capital Formation and Local Economic Performance', Regional Studies, 30, pp. 1-14.

Chandra, S., (2005), 'Composition, Similarity and the Measurement of Economic Homogeneity', Journal of Regional Science, 45, pp. 591-616.

Cheshire, P.C., (1973), Regional Unemployment Differentials in Great Britain, Cambridge University Press, National Institute of Economic and Social Research.

Decressin, J. and Fatás, A., (1995), 'Regional Labour Market Dynamics in Europe', European Economic Review, 39, pp. 627-55.

Diamond, C.A. and Simon, C.J., (1990), 'Specialisation and the Returns to Labor', Journal of Labor Economics, 8, pp. 175-201.

Dixon, R.J. and Thirlwall, A.P., (1975), Regional Growth and Unemployment in the United Kingdom. London: Macmillan.

Erdem, E. and Glyn, A., (2001), Job Deficits in UK Regions', Oxford Bulletin of Economics and Statistics, 63, pp. 737-52.

Faggio, G. and Nickell, S., (2005), 'Inactivity Among Prime Age Men in the UK', CEP Discussion Paper no. 673, Centre for Economic Performance, London School of Economics. 
Fothergill, S., (2001), 'The True Scale of the Regional Problem in the UK', Regional Studies, 35, pp. 241-6.

Fothergill, S. and Gudgin, G., (1982), Unequal Growth. London: Heinemann.

Glaeser, E.L., Kallal, H.D., Scheinkman, J.A., and Shleifer, A., (1992), 'Growth in Cities', Journal of Political Economy, 100, pp. 1126-52.

Green, A.E. and Owen, D., (2006), The Geography of Poor Skills and Access to Work, Joseph Rowntree Foundation, York.

Griffiths, A. and Wall, S. (eds.), Applied Economics, 10 ${ }^{\text {th }}$ edition. Harlow: Financial Times Prentice Hall.

Im, K., Pesaran, M.H., and Shin, Y., (2003), 'Testing for Unit Roots in Heterogeneous Panels', Journal of Econometrics, 115, pp. 53-74.

Lilien, D.M., (1982), 'Sectoral Shifts and Cyclical Unemployment, Journal of Political Economy, 90, 777-93.

Lucas, R. and Prescott, E., (1974), 'Equilibrium Search and Unemployment', Journal of Economic Theory, 7, pp. 188-209.

Machin, S., (1996), 'Changes in the Relative Demand for Skills in the UK Labour Market', in A. Booth and D. Snower (eds.), Acquiring Skills, Cambridge University Press, Cambridge.

Marshall, A., (1920), Principles of Economics. London: Macmillan.

Neumann, G.R. and Topel, R.H., (1991), 'Employment Risk, Diversification and Unemployment', Quarterly Journal of Economics, 106, pp. 1341-65.

O'Leary, N., Murphy, P.D., Latreille, P., Blackaby, D.H., and Sloane, P.J., (2005), 'Accounting for Differences in Labour Market Outcomes in Great Britain: A Regional Analysis Using the Labour Force Survey', mimeo, Economics Department, University of Wales Swansea.

Pesaran, M.H., (2005), 'A Simple Panel Unit Root Test in the Presence of CrossSection Dependence', DAE Working Paper no. 0346, University of Cambridge.

Robson, M., (2006), 'Sectoral Shifts, Employment Specialisation and the Efficiency of Matching: Evidence from UK Regional Labour Markets', Regional Studies, forthcoming.

Rosenthal, S. S. and Strange, W.C., (2004), 'Evidence on the Nature and Sources of Agglomeration Economies', in Henderson, J.V. and Thisse, J-F. (eds.), Handbook of Regional and Urban Economics, Volume 4. Amsterdam: Elsevier.

Rowthorn, R., (2000), 'The Political Economy of Full Employment in Modern Britain', Oxford Bulletin of Economics and Statistics, 62, pp. 139-73. 
Shearmur, R. and Polèse, M., (2005), 'Diversity and Employment Growth in Canada, 1981-2001: Can Diversification Policies Succeed?', The Canadian Geographer, 49, pp. 272-90.

Simon, C.J., (1988), 'Frictional Unemployment and the Role of Industrial Diversity', Quarterly Journal of Economics, 103, pp. 715-28.

Taylor, J. and Bradley, S., (1983), 'Spatial Variations in the Unemployment Rate; a Case Study of North West England', Regional Studies, 17, pp. 113-24.

Taylor, J. and Bradley, S., (1994), 'Spatial Disparities in the Impact of the 19901992 Recession: an analysis of UK Counties', Oxford Bulletin of Economics and Statistics, 56, p. 367-82.

Wren, C. and J. Taylor, (1999), Industrial Restructuring and Regional Policy, Oxford Economic Papers, 51, 487-516. 